\title{
The Platform Economy After COVID-19: Regulation and the Precautionary Principle
}

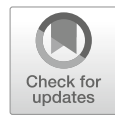

\author{
Cristiano Codagnone
}

\begin{abstract}
Online platforms are two-sided or multisided markets whose main function is matching different groups (of producers, consumers, users, advertisers, i.e., hosts and guest in Airbnb, audiences and advertised in Google, etc.) that might otherwise find it more difficult to interact and possibly transact. Some of the potential critical issues associated with the platform economy include the relationship between personhood (the quality and condition of being an individual person with protected sphere of privacy and intimacy) and personal data, on which the platform economy thrives by extracting behavioral surplus, scale to dominance and market power, and lockin for businesses. In this chapter, I first shortly review how the pandemic crisis has impacted the platform economy and what problems are being exacerbated. I then conclude and focus the core part of my analysis on the issue of regulation and particularly on the merits and limits of applying the precautionary principle when addressing the online platform economy.
\end{abstract}

\section{Introduction}

Online platforms are two-sided or multisided markets whose main function is matching different groups (of producers, consumers, users, advertisers, i.e., hosts and guest in Airbnb, audiences and advertised in Google, etc.) that might otherwise find it more difficult to interact and possibly transact. The economic theory explains how value generation and profit making rely on crossed network externalities: value on one side of the market depends on positive network externalities on the other side. In some cases, gratuity is the optimal price setting on one side of the market (e.g., Facebook). It also explains the specific nature of unpaid digital labor, that is, users providing "labor," in the case of Facebook in the form of content creation, without receiving a monetary remuneration. Platforms internalize these network externalities, by facilitating the matching between sides and reducing transaction costs. The

\footnotetext{
C. Codagnone $(\bowtie)$

Dipartimento di Scienze Sociali e Politiche, Università degli studi di Milano, Milano, Italy e-mail: Cristiano.codagnone@unimi.it
} 
central features of platforms are direct and/or indirect network effects. In platforms, more users beget more users, a dynamic which in turn triggers a self-reinforcing cycle of growth. Platforms represent a new structure for organizing economic and social activities and appear as a hybrid between a market and a hierarchy. They are match makers like traditional markets, but they are also company heavy in assets and often quoted in the stock exchange. Platforms, therefore, are not simply technological corporations but a form of "quasi-infrastructure." Indeed, in their coordination function, platforms are as much an institutional form as a means of innovation.

In my previous work on the topic (Bogliacino et al. 2020; Codagnone et al. 2019; Mandl and Codagnone 2021), I discussed some of the potential critical issues associated with the platform economy. First, there is the relationship between personhood (the quality and condition of being an individual person with protected sphere of privacy and intimacy) and personal data, on which the platform economy thrives by extracting behavioral surplus (Zuboff 2019). The extraction of personal behavioral data, including about things one may consider very personal and secrets, is a violation of personhood as defined above. In particular, "loss of control over personal information creates a variety of near-term and longer-term risks that are difficult for individuals to understand - and, importantly for antitrust purposes, therefore impossible for them to value" (Cohen 2019, p. 175). Access to such personal data enables companies to "hyper-nudge" consumers (Yeung 2017). Short-circuiting behavioral data and algorithmic learning, online platforms enact very powerful nudges guiding decisions and reducing consumers' autonomous choices. Second, there is the problem of competition and the potential monopolistic or oligopolistic outcomes of the platform economy, considering also the number of merger and acquisitions (M\&A) completed by the most powerful of them (so-called GAFAM - Google, Amazon, Facebook, and Apple) between 2013 and 2019 (see, for instance, Lechardoy et al. 2021, pp. 46-47). Third, the platform economy, and especially online labor platform, is contributing to the fragmentation of work and to the rise of new precarious work forms (Mandl and Codagnone 2021).

In this chapter, using information mostly from the European Commission "Observatory on the Online Platform Economy" (https://platformobservatory.eu/ and the analytical paper by Lechardoy et al. 2021), I first shortly review how the pandemic crisis has impacted the platform economy and what problems are being exacerbated. I then conclude and focus the core part of my analysis on the issue of regulation and particularly on the merits and limits of applying the precautionary principle when addressing the online platform economy.

\section{The Effects of the Pandemic}

The COVID-19 pandemic has created a unique situation leading to an acceleration of digital transformation and digitization. The COVID-19 crisis has increased the use of online services and the breadth of users. A recent report by the Joint Research Centre (JRC, the research harm of the Commission) concludes that as a game changer, 
COVID-19 is acting as a booster of both potential opportunities and of concerns/ risks for the digital transformation (Craglia et al. 2020). The opportunities are those of further innovation, economic growth, as well as increase in efficiency and effectiveness of public services. The risks include above all the deepening of the digital divide, the scale to dominance by incumbents, and the issue of personal data and surveillance. The acceleration in the pace of digitization has also exposed the opportunities and weaknesses of the online platform economy. For what concerns the latter, the main effects of the pandemic reported by the earlier cited Online Observatory (https://platformobservatory.eu/) and related analytical paper (Lechardoy et al. 2021) are four.

First, the Observatory surveys show that during the crisis business users have increasingly relied on online platforms despite the fact that the revenues generated through them decreased. There is little evidence of switching, which suggests the pandemic crisis has reinforced lockins.

Second, traffic and revenue share have increased for social media, search engines, and some national marketplaces, while they have decreased for platforms in the tourism and travel sectors. The top 5 platforms (Google, Apple, Facebook, Amazon, Microsoft) have increased their audience and recorded sizeable profits also in 2020. On the other hand, the pandemic accelerated the digital transition of health and education, where new platforms are emerging.

Third, the GAFAM incumbents have kept being active in M\&A, purchasing companies to either strengthen their current products and services or expand into adjacent markets and consolidate their ecosystem. Since the pandemic has not weakened but rather reinforced the economic position of incumbent platforms, it is reasonable to expect that they will continue in their M\&A activism in the near future. In view also of the fact that given the monetary threshold for M\&A to attract regulators' attention, many M\&A of small but innovative companies occur below the regulators' radar.

Fourth, many traditional business players (non-IT companies) are under dire condition of crisis due to the effect of the pandemic abilities to recover and to innovate. This may further reinforce the market position of platform payers that may appropriate new market shares.

Last but not least, online platform and related apps entered also directly into the business of tackling and containing the pandemic. Smart solutions enabled by online platform, has been argued, could improve detection and alerting (more effective and precise), as well as enable faster containment actions and leveraging positively existing infrastructures. So, dozens of online apps and platforms mushroomed for track and tracing. In April 2020, Apple and Google announced a partnership to enable the use of Bluetooth Low Energy technology for COVID-19 contact tracing, and in September 2020, Apple and Google announced that they would integrate their contact tracing technology into their next mobile operating systems claiming that health authorities would not need to build their own tracing apps but can simply configure the basic software framework to their country's needs. This development, however, has raised concerns on privacy and personal data and about the risk that, after the emergency would be over, our society could drift by inertia toward more 
systemic surveillance. Furthermore, it has been observed that the pandemic has helped incumbents such as Google to regain legitimacy and momentum (Cinnamon 2020).

\section{Regulation and the Precautionary Principle}

As reviewed, the effects of COVID-19 have increased some of the policy concerns surrounding the online platform economy. Concerns that before the pandemic outbreaks were high on the regulators agenda with a debate polarized basically among two positions.

The first is the libertarian and impossibility statement position. According to this view, any attempt to regulate online platform and more broadly the current digital transformation (including Artificial Intelligence, AI) would stifle innovation and produce undesirable side effects. In extreme fashion, this discourse can be summarized with the view that regulation is the mortal enemy of innovation (Cohen 2019, p. 178). Hence, for the sake of economic growth and innovation, matters should be deregulated, and/or their governance should be devolved to the private sector through various forms of self-regulation and de facto standardization. A corollary of this discourse is that attempts at regulation are touted as new forms of protectionism. A second discourse takes the form of an "impossibility statement." Regulation of current development is and will remain technically complex and beyond the reach of the cognitive tools and processes available to regulators. The impossibility statement implication is that in the age of algorithmic governance emerging as a new form of business strategy, regulators cannot keep up and should only hope and wait until algorithms improve and better self-regulate themselves.

The most sustained counterargument has been developed by law scholar Juliet Cohen who argues that the current digital transformation requires regulatory innovation not only on the "what" (new rubrics of activities needing regulation) but also on the "how," meaning entering the domain of algorithmic governance (2019, 812-185 and 200-201). Cohen and other scholars of the digital transformation are in favor of applying the precautionary principle to regulate, for instance, the way platforms gather personal data that generates a behavioral surplus. To a large extent, the difference between a precautionary approach to regulation and a cost-benefit one is how the object of analysis is positioned between the two poles of uncertainty and risk. Under high uncertainty and the possibility that no regulation would produce serious harms, then a precautionary approach would favor introducing regulation a priori to preempt such harms. The best analogy is with the introduction of lockdowns across entire population without any cost-benefit analysis based on the uncertain but serious danger of wider spread and more deaths from COVID-19.

So, given the complexity and uncertainty surrounding the development of platforms and related technologies, Cohen argues to move from a risk perspective backing a cost-benefit approach to introducing policy and regulation based on the precautionary principle. Competition regulation in the context of the digital 
transformation and with specific respect to online platforms requires a radical renewal of a regulatory regime that was developed for the industrial era and as such is no longer appropriate or useful. In sum, the view juxtaposed to the approach "leave it to the market" is that the current digital transformation requires a bottom-up rethinking of competition and the imposition of a public utility regulatory regimes on platforms. The possibility of imposing common carriage/public utility requirements on online platform can be justified in view of some of the considerations I placed in the introduction. Given their de facto role as "quasi-infrastructures" and "quasiinstitutions," and also considering their prominence during the pandemic, this could be the good moment to adapt the industrial era notions of common carriage and/or public utility provision to the networked information age and particularly to online platforms. The argument goes that regulation of the digital world should incorporate public access and social justice considerations.

\section{Conclusions}

Without entering into the merits of the two opposing positions characterized above, I am going to conclude this chapter with a discussion of the application of the precautionary principle versus a case-by-case cost-benefit analysis as different approaches to regulation.

The application of the precautionary principle turns the complexity and uncertainty argument, often used by libertarian and/or tech lobbyists, on its head. According to Cohen (2019), for instance, platformization and algorithmic governance create such level of complexity and uncertainty that warrant moving away from a risk perspective backing a cost-benefit approach to policy and regulation to an uncertainty perspective backing a precautionary approach that would prescribe intervening with regulation. From this perspective, a precautionary approach should be adopted, and more stringent regulation enacted when uncertainties concern crucial and value-relevant issues. On the other hand, the precautionary approach has been criticized as "the law of fear" and considered inferior to cost-benefit analysis approach to policy issues on a case-by-case level (Sunstein, 2005). Although reasonable a priori, the precautionary principle is usually contested on two grounds: (a) if regulation is defended on the principle of the worst scenario, then a lack of regulation can be defended by the same argument when the consequences of strict regulations are potentially very negative; and (b) the precautionary principle claims that dangers should not be downplayed, but this exposes the risk of building a negative public discourse that would block innovators.

There is a point in Sunstein's critique of the precautionary principle, in that by reacting to uncertainty and complexity with across-the-board regulation may end up stifling true innovation without cutting the nails of the incumbents. There are many innovative platforms, and not all of them are or will become as GAFAM. The latter and the concerns they raise can only be dealt with new competition policy instruments and cases and with political will to do so. On the other hand, regulators should 
incentivize relevant actors to adopt governance standards and procedures that will support their efforts to operationalize trustworthy digital transformation and online platform economy. Furthermore, they should support the development of technologies, systems, and tools to help relevant actors identify and mitigate relevant risks. This means incentivizing organizations to adopt robust internal governance and equipping them with tools to identify and mitigate risk is considered more effective than a regulatory regime that mandates specific outcomes. New regulation should support ongoing efforts to build best practices, rather than risk cutting them short with inflexible rules that may not be able to adapt to a rapidly changing field of technology.

In conclusion, regulators should carefully weigh the pros and cons of policy responses adopting the precautionary principles and those that support a case-bycase cost-benefit analysis before introducing any new piece of legislation.

\section{References}

Bogliacino, F., Codagnone, C., Cirillo, V., \& Guarascio, D. (2020). Quantity and quality of work in the platform economy. In K. Zimmermann (Ed.), Handbook of Labour, Human Resources and Population Economics. London: Springer Nature.

Cinnamon, J. (2020). Platform philanthropy, 'public value', and the COVID-19 pandemic moment. Dialogues in Human Geography, 10 (2), pp. 242-245.

Codagnone, C., Karatzogianni, A., \& Matthews, J. (2019). Platform Economics: Rhetoric and Reality in the 'Sharing Economy'. Bingley, United Kingdom: Emerald Publishing Limited.

Cohen, J. (2019). Between Truth and Power: The Legal Constructions of Informational Capitalism. Oxford: Oxford University Press.

Craglia, M. et al. (2020). Artificial Intelligence and Digital Transformation: early lessons from the COVID-19 crisis. Luxembourg: Publications Office of the European Union.

Lechardoy, L., Sokolyanskaya, A. \& Lupiáñez- Villanueva, F. (2021). Analytical paper on the structure of the online platform economy post COVID-19 outbreak. Brussels: Observatory on the Online Platform Economy, European Commission.

Mandl, I., \& Codagnone, C. (2021). The Diversity of Platform Work - Variations in Employment and Working Conditions. In H. Schaffers, M. Vartiainen, \& J. Bus (Eds.), Digital Innovation and the Future of Work (pp. 177-195). Gistrup, Denmark: River Publishers.

Sunstein, C. (2005). The Law of Fear. Cambridge: Cambridge University Press.

Yeung, K. (2017). 'Hypernudge': Big Data as a mode of regulation by design. Information, Communication \& Society, 20(1), 118-136.

Zuboff, S. (2019). The Age of Surveillance Capitalism. London: Profile Books Ltd. 
Open Access This chapter is licensed under the terms of the Creative Commons Attribution 4.0 International License (http://creativecommons.org/licenses/by/4.0/), which permits use, sharing, adaptation, distribution and reproduction in any medium or format, as long as you give appropriate credit to the original author(s) and the source, provide a link to the Creative Commons license and indicate if changes were made.

The images or other third party material in this chapter are included in the chapter's Creative Commons license, unless indicated otherwise in a credit line to the material. If material is not included in the chapter's Creative Commons license and your intended use is not permitted by statutory regulation or exceeds the permitted use, you will need to obtain permission directly from the copyright holder. 